\title{
The protective effect of Jangkanghwan (Korean traditional food) on lipopolysaccharide-induced disruption of the colonic epithelial barrier
}

\author{
Xingyao Long ${ }^{1,2}$, Yong-kyu Kim³ ${ }^{3}$ Ting Yu ${ }^{1}$, Ruokun Yi ${ }^{2}$, Xin Zhao ${ }^{2^{*}}$ (i) and Kun-young Park ${ }^{1,2^{*}}$
}

\begin{abstract}
Jangkanghwan $(\mathrm{JKH})$ is a Korean traditional food that is a mixture of food ingredients and traditional Korean medicine ingredients, and it has been observed to produce satisfactory anti-inflammatory, antioxidant, and antibacterial effects. In the current study, JKH was administered by gavage to BALB/C mice with lipopolysaccharide (LPS)-induced colonic epithelial dysfunction, and mouse body weight and food intake were recorded. Indexes such as colonic paracellular permeability, serum inflammatory cytokines, and bacterial translocation were used to comprehensively evaluate the regulatory effect of JKH on mouse colonic epithelial function, and QPCR and Western blot were also used to analyze the expression of tight junction (TJ)-related genes, such as occludin, claudin, zonula occludens (ZOs) proteins, and junction adhesion molecules (JAM) in the colonic epithelial tissue. The experimental results indicated that JKH relieved the edema of the liver, spleen, and mesenteric lymph node tissues, and reduced the loss of appetite and diarrhea caused by LPS injection in mice. It increased the amount of mice food intake from $3.7 \mathrm{~g} /$ day in the LPS group to $4.7 \mathrm{~g}$ per day; the water content in the feces of mice in the JKH group was $13.86 \%$ less than that in the LPS group. JKH reduced the inflammatory response in mice caused by LPS, protected the integrity of the colon, the permeability of fluorescent macromolecules was one-fourth of the LPS group, and enhanced the mRNA and protein expression of TJrelated proteins in colon tissue. Our findings highlight that JKH has benefits in intestinal health and relieving systemic inflammation, relevant aspects of its use as a functional food.
\end{abstract}

Keywords: Jangkanghwan, Lipopolysaccharide (LPS), Colonic epithelial barrier, Bacteria translocation

\section{Introduction}

Jangkanghwan $(\mathrm{JKH})$ is a Korean traditional food that composed of 12 ingredients, of which some are food ingredients and others are traditional Korean

\footnotetext{
*Correspondence: zhaoxin@cque.edu.cn; kunypark@cha.ac.kr ${ }^{1}$ Department of Food Science and Biotechnology, Cha University, Seongnam, Gyeonggi-do 13488, South Korea

${ }^{2}$ Chongqing Collaborative Innovation Center for Functional Food, Chongqing Engineering Research Center of Functional Food, Chongqing Engineering Laboratory for Research and Development of Functional Food, Chongqing University of Education, Chongqing 400067, People's Republic of China

Full list of author information is available at the end of the article
}

medicine (TKM) ingredients. Among them, radish leaves (Mucheong; Brassica rapa L.), Plantago asiatica L. (Chajeonyeop), Cirsium japonicum var. ussuriense (Regel) Kitam. (Daegye), Saururus chinensis (Lour.) Baill. (Sambaekcho), and Atractylodes macrocephala Koidzumi (Baekchul) are the most abundant ingredients [1]. According to ancient medicinal works and modern Korean medicine studies, all of the above components exert anti-inflammatory [2], anti-bacterial [3], anti-oxidant effects [4], and some also have anti-cancer and antitumor effects [5].

It has been previously demonstrated that TKM has a regulatory effect on the mucosal barrier function of the 
intestine [6]. TKM is usually used clinically by decoction [7]. After entering the intestinal tract, most of its active ingredients are metabolized and transformed with the intestinal flora to change their natural prodrug components, which are then absorbed through the intestines to exert their clinical effects [8]. A few components are directly absorbed in their original form, and others are absorbed by the intestine after they undergo metabolic reactions such as binding and lysis with the intestinal microbiota [9]. Relevant clinical studies have confirmed that TKM has an advantageous effect on promoting the proliferation of probiotics, inhibiting the growth of pathogenic bacteria, and restoring the diversity and improving the balance of the intestinal flora [10].

Traditional herbal medicines consist of plants that are rich in a variety of alkaloids, polysaccharides, glycosides, proteins, amino acids, and other ingredients [11]. The effective ingredients and their metabolites can be used by intestinal probiotics, but not by pathogenic bacteria, thereby selectively promoting probiotic proliferation and inhibiting the growth of pathogenic bacteria [12]. The organic acids in traditional Korean medicines can also acidify the intestinal environment, lower the $\mathrm{pH}$ of the intestine, and provide an adapted environment for the growth of probiotics [13].

In addition to normal digestion, absorption, and excretion, the intestine also has an important barrier function [14]. The intestinal mucosal barrier is a relatively complete functional isolation zone of the normal intestine, and it prevents harmful pathogens from entering human tissue cells, organs, and blood circulation through the intestinal mucosa, thereby preventing a series of pathological reactions [15]. There are many bacteria, viruses, and their toxins in the normal human intestinal tract. The intestinal barrier separates the intestinal cavity from the internal environment of the body to maintain a relatively stable environment in the body and ensure the normal life activities of the body [16]. However, under the action of factors such as severe trauma, infection, and stress, the intestinal mucosal barrier can be damaged to varying degrees, which can cause bacteria and endotoxins in the intestine to enter the blood circulation through the intestinal barrier, causing intestinal endotoxemia or sepsis [17].

In recent years, TKM has made great progress in the treatment of impaired intestinal mucosal barrier function, and its advantages have become increasingly prominent. The TKM ingredients in JKH give it the character of a pharmaceutical product, but the food ingredients contained in it also allow JKH to be used as a health food. Therefore, in the current study, we examined the protective effect of $\mathrm{JKH}$ as a traditional functional food and medicine on the mouse colonic epithelial barrier and the preventive effect of inflammation through gavage of LPSinduced colonic epithelial barrier damage mice with JKH.

\section{Materials and methods Introduction of JKH}

Experimental JKH was kindly provided by Gahwa Well Food Co., Ltd. (Jincheon, Chungcheongbuk-do, Korea). Information regarding JKH has been previously described. JKH is composed of 12 substances: Mucheong (radish leaves, Brassica rapa L.) (19.2\%), Chajeonyeop (Plantago asiatica L.) (12.4\%), Daegye (Cirsium japonicum var. ussuriense (Regel) Kitam.) (11.1\%), Sambaekcho (Saururus chinensis (Lour.) Baill.) (10.2\%), Baekchul (Atractylodes macrocephala Koidzumi) (10.2\%), Gokgisaeng (Viscum album var. coloratum) (9.5\%), Baekgang (Zingiber officinale Roscoe) (9.5\%), Gonpo (Saccharina japonica) (8.7\%), Nabok (dried radish, Raphanus sativus L.) (2.6\%), Chaga mushroom (Inonotus obliquus (Ach. ex Pers.) Pilát) (2.6\%), Nalgye (Cinnamomum cassia Blume) (2.6\%), and Jukyeom (bamboo salt) (1.4\%) [1].

\section{Animal experimental design}

Forty 7-week-old BALB/C mice weighing $20.0 \pm 2.0 \mathrm{~g}$ were randomly divided into four groups after 1 week of adaptive feeding, with 10 mice in each group. All mice had free access to AIN-93G diet food and tap water during the 17-day experiment. The normal group and LPS group mice were gavaged with tap water every day, and the JKH Low-dose (JKHL) group $(700 \mathrm{mg} / \mathrm{kg} \mathrm{BW})$ and $\mathrm{JKH}$ High-group (JKHH) group (2100 mg/kg BW) [1] mice were gavaged daily according to the concentration of JKH solution. On days 15, the mice in the normal group were intraperitoneal injected with physiological saline, and the remaining 30 mice were intraperitoneal injected with $30 \mathrm{mg} / \mathrm{kg}$ BW LPS solution. The food intake of the mice was weighed daily, and feces were collected [18].

After all experiments were completed, $\mathrm{CO}_{2}$ treatment was used to euthanize the mice, and then, orbital venous blood collection was performed. The liver, kidney, and intestinal lymph nodes were removed while the mouse was on a sterile operating table, and then, the organs were weighed. The colon was completely removed, its length was measured, it was photographically recorded, and then, it was stored at $-80{ }^{\circ} \mathrm{C}$ for later use (Fig. 1). The animal study was reviewed and approved by the protocol for these experiments was approved by the Ethics Committee of Chongqing Collaborative Innovation Center for Functional Food (202101005B), Chongqing, China. The experimental process was in accordance with 2010/63/EU directive. 


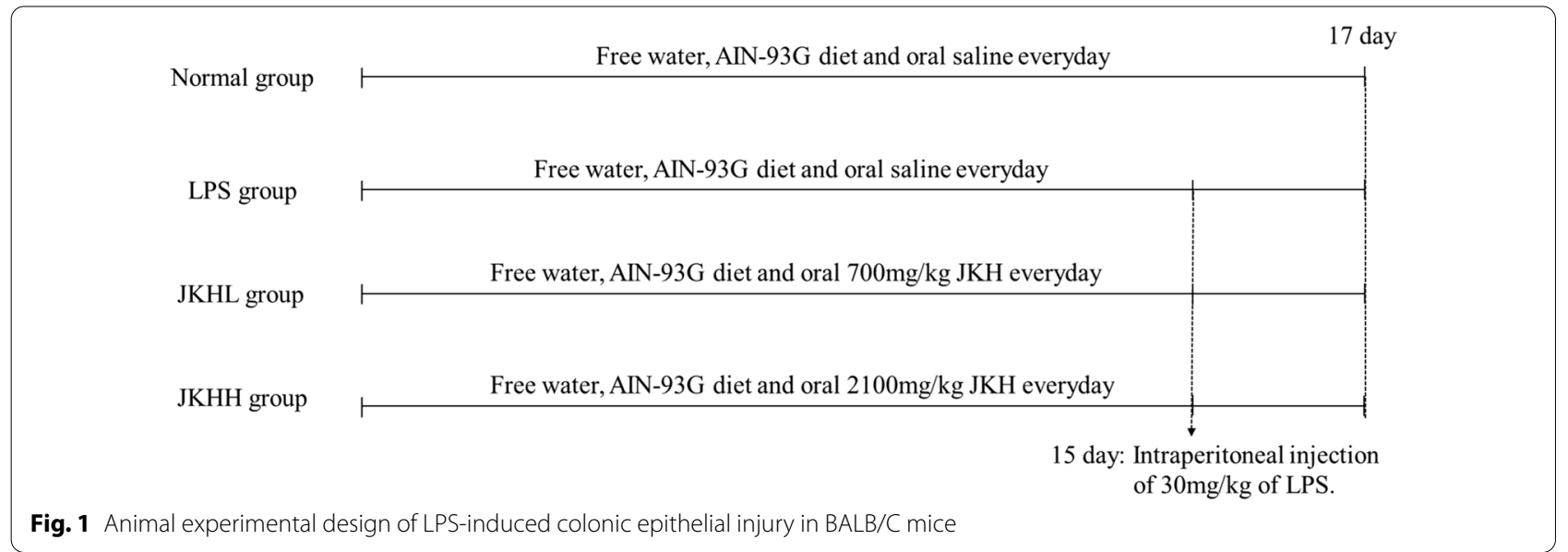

\section{Diarrhea after LPS administration}

The mouse feces collected daily were weighed and recorded, dried in an oven at $55{ }^{\circ} \mathrm{C}$ for $48 \mathrm{~h}$, placed in a drying dish to equilibrate to room temperature, and the dried feces were then weighed. The above operation was repeated until the stool weight difference was less than $1 \%$, and then, the dry weight of the stool was recorded.
According to the ELISA kit instructions, the levels of IL-1 $\beta$, IL-6, TNF- $\alpha$, and IFN- $\gamma$ in mouse serum were measured.

\section{H\&E staining of colon tissue}

Colon tissues were prepared for histopathological analysis after fixation in neutral buffered formalin (buffered 10\% formaldehyde, $\mathrm{pH}$ 7.2). Paraffin sections of $5-\mu \mathrm{m}$ thickness

Fecal moisture content $(\%)=$ Dry weight of feces $(g) /$ Wet weight of feces $(g) \times 100$.

\section{Bacterial translocation assay}

The liver, kidney, and mesenteric lymph nodes (MLN) were weighed and then homogenized. Each of the tissue homogenates was spread $(0.1 \mathrm{~mL})$ on plate count agar (PCA). After anaerobic incubation at $37{ }^{\circ} \mathrm{C}$ for $24-48 \mathrm{~h}$, the number of colonies was counted according to the colony dilution factor, subsequently converted to the amount of bacteria per gram of tissue, and expressed in colony-forming units (CFUs). Greater than $100 \mathrm{CFU} / \mathrm{g}$ was recorded as a positive plate, and less than $100 \mathrm{CFU} / \mathrm{g}$ was recorded as a negative plate [19].

\section{Determination of the intestinal mucosa permeability}

Food and water were withheld from the mice for $4 \mathrm{~h}$ before they were killed. In the meantime, fluorescein isothiocyanate-dextran (FITC-D, MW 4000) was used to intragastrically (60 mg FITC-D/100 g) the mice. After $4 \mathrm{~h}$, the serum was collected, and the fluorescence density of each sample was measured with a microplate reader at an excitation wavelength of $485 \mathrm{~nm}$ and the emission wavelength of $528 \mathrm{~nm}$ to determine the concentration of FITC-D in the serum [20].

\section{Serum inflammatory cytokine test}

The collected mouse blood was centrifuged at $3000 \times g$ and $4{ }^{\circ} \mathrm{C}$ for $10 \mathrm{~min}$, and then, the serum was collected. were processed for hematoxylin and eosin (H\&E) staining. The slices were observed, and photographs were obtained via optical microscope (BX43, OLYMPUS, Tokyo, Japan).

\section{qPCR}

For qRT-PCR, $100 \mathrm{mg}$ colon tissue was homogenized with $1 \mathrm{~mL}$ TRIzol reagent (Invitrogen, Carlsbad, CA, USA) to extract RNA from the tissue, and the RNA concentration was adjusted to $1 \mu \mathrm{g} / \mu \mathrm{L}$. A cDNA reverse transcription kit (Thermo Fisher Scientific, USA) was used to reverse transcribe the RNA to cDNA. The synthesized cDNA was then mixed with $10 \mu \mathrm{L}$ SYBR Green PCR Master Mix (Thermo Fisher Scientific, USA), $2 \mu \mathrm{L}$ primers (Table 1), and distilled water. Quantitative PCR was performed in an automatic qPCR thermocycler at $95{ }^{\circ} \mathrm{C}$ for $60 \mathrm{~s} ; 40$ cycles at $95{ }^{\circ} \mathrm{C}$ for $15 \mathrm{~s}, 55^{\circ} \mathrm{C}$ for $30 \mathrm{~s}$, and $72{ }^{\circ} \mathrm{C}$ for $35 \mathrm{~s}$; and a final step of $95{ }^{\circ} \mathrm{C}$ for $30 \mathrm{~s}$ and $55^{\circ} \mathrm{C}$ for $35 \mathrm{~s}$. Glyceraldehyde-3-phosphate dehydrogenase (GAPDH) was used as the internal reference gene, and the $2^{-\Delta \Delta \mathrm{Ct}}$ formula was used to calculate the relative mRNA transcription level.

\section{Western blot}

For the Western blot, $100 \mathrm{mg}$ of colon tissue was homogenized with $1 \mathrm{~mL}$ radioimmunoprecipitation assay (RIPA, Thermo Fisher Scientific, USA) and $10 \mu \mathrm{L}$ phenylmethylsulfonyl fluoride (PMSF, Thermo Fisher 
Table 1 Primer sequences of colon tight junctions (TJS) in BALB/C mice that underwent LPS-induced colonic epithelial injury

\begin{tabular}{lll}
\hline Gene & Forward sequence & Reverse sequence \\
\hline JAM-1 & 5'-TGGCATTGGGCAGTGTTACAG-3' $^{\prime}$ & $5^{\prime}$-GGCATTCCTGCTGGTTACA-3' \\
ZO-1 & $5^{\prime}$-AGGACACCAAAGCATGTGAG-3' & $5^{\prime}$-GCGTCATTCACTTCGAGCAGA-3' \\
Claudin-1 & $5^{\prime}$-GTTTGCAGAGACCCATCAC-3' & $5^{\prime}$-AGAAGCCAGGATGAAACCCA-3' \\
Occludin & $5^{\prime}$-CTCCCATCCGAGTTTCAGGT-3' & $5^{\prime}$-GCTGTCGCCTAAGGAAAGAG-3' \\
Cingulin & 5'-CTAAACCGACTTCCTCGATTAA-3' & $5^{\prime}$-TGTTGATGAGCGAGTCCACTG-3' \\
GAPDH & 5'-AAGGTGAAGGTCGGAGTCAAC-3' & $5^{\prime}$-AAGGTGAAGGTCGGAGTCAAC-3' \\
\hline
\end{tabular}

Scientific, USA), and then centrifuged at $12,000 \times g$ for 5 min at $4{ }^{\circ} \mathrm{C}$. The protein was quantified using a bicinchoninic acid (BCA) protein assay kit (Thermo Fisher Scientific, USA). The protein samples were mixed with sample buffer (Thermo Fisher) 4:1, heated at $95{ }^{\circ} \mathrm{C}$ for $5 \mathrm{~min}$, and then, the samples were loaded into the wells of a sodium dodecyl sulfate-polyacrylamide gel electrophoresis (SDS-PAGE) gel, and the gel was electrophoresed at $100 \mathrm{~V}$. The bands on the SDSPAGE gel were transferred to a polyvinylidene difluoride (PVDF) membrane. Then, the PVDF membrane was blocked with $5 \%$ skimmed milk for $1 \mathrm{~h}$ and incubated with primary antibody (JAM-1: BS-3651R; ZO-1: 40-2200; Claudin-1: 71-7800; Occludin: 40-4700; Cingulin: 651122; beta-actin: MA5-11869, Thermo Fisher Scientific, USA) overnight at $4{ }^{\circ} \mathrm{C}$. The membrane was washed, secondary antibody (Thermo Fisher Scientific, USA) was added, and the blot was incubated for $1 \mathrm{~h}$. Western enhanced chemiluminescence (ECL) substrate (Thermo Fisher Scientific, USA) was used to perform chemiluminescence visualization, and images were obtained using iBright (Thermo Fisher Scientific, USA) for subsequent analysis.

\section{Statistical analysis}

Three measurements of serum and tissue samples were performed in parallel, and the average value was calculated. SPSS software (SPSS v.25 for Windows, IBM Software Group, Chicago, IL, USA) was used to average and analyze the data. The Duncan multiple range test was used to evaluate the difference between the mean values for each group by one-way analysis of variance (ANOVA). Differences with $\mathrm{p}<0.05$ were considered statistically significant.

\section{Results}

\section{Food intake analysis}

The administration of LPS by injection can cause pain in mice, which leads to decreased appetite and food intake. During the 17-day experiment, the dietary intake of all mice in the first 15 days was nearly the same, $5.0 \pm 0.16 \mathrm{~g}$. However, after the LPS injections were initiated on the 15 th day, all mice except those in the normal group showed a decrease in food intake that continued until the end of the experiment. Among them, the decrease in food intake of the LPS group mice was the greatest, with consumption measured at $3.7 \pm 0.15 \mathrm{~g}$ on the 17th day. The food intake of the JKHH group and JKHL group mice on the 17th day was $4.7 \pm 0.21 \mathrm{~g}$ and $4.0 \pm 0.11 \mathrm{~g}$, respectively. It can be clearly seen that JKH can alleviate the decreased food intake in mice (Fig. 2a).

\section{Organ index analysis}

The weight of mice and organ weights indicate that LPS causes weight loss in mice, but it will cause the liver, kidneys, and MLN to increase in weight. Therefore, the liver, kidney, and MLN indexes for all LPS-induced mice all increased by different degrees compared with the normal group mice. Among them, the greatest increase was for the LPS group mice, and they exhibited an organ index that was approximately twice that of the normal group. JKH relieved the edema of organs in mice, with a stronger effect at higher concentrations (Table 2).

\section{Diarrhea after LPS administration}

The water content of mouse feces was measured to express the severity of diarrhea caused by LPS in mice. Through experimentation (Fig. 2b), in the first 15 days, the average fecal water content of mice was $56.19 \pm 0.53 \mathrm{~g}$. After the injection of LPS on the 15th day, the mouse feces became soft and thinner on the 16th day. The water content of feces significantly increased on day 16-17, especially on day 17 . The fecal water content of mice in the LPS-induced group increased to $121.23 \%$ of the average fecal water content of the previous 15 days. The fecal water content of the JKHL and JKHH group mice was lower than that of the LPSinduced group, which was $115.30 \%$ and $107.37 \%$ of the average fecal water content during the previous 15 days, respectively. 

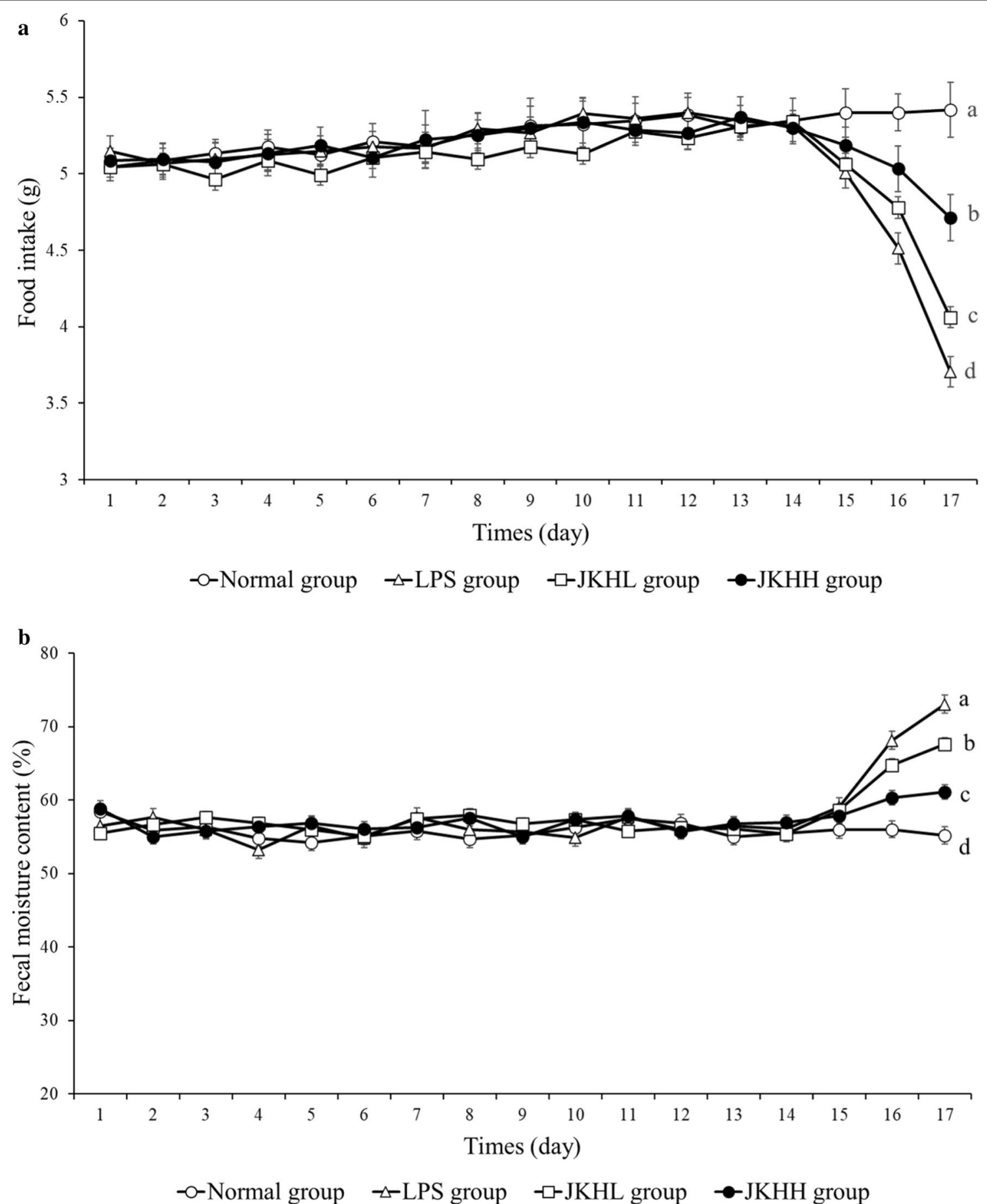

Fig. 2 Daily food intake (a) and fecal moisture content (b) of BALB/C mice that underwent LPS-induced colonic epithelial injury. ${ }^{a-d}$ Mean values with different letters in the different polyline are significantly different $(p<0.05)$ according to Duncan's multiple range test. LPS: 30 mg/ kg BW injection on 15 days; JKHL, low dose of JKH (700 mg/kg BW) + LPS 30 mg/kg BW injection on 15 days; JKHH, high dose of JKH (2100 mg/ $\mathrm{kg} \mathrm{BW})+$ LPS $30 \mathrm{mg} / \mathrm{kg} \mathrm{BW}$ injection on 15 days 
Table 2 Organ indexes of BALB/C mice that underwent LPS-induced colonic epithelial injury

\begin{tabular}{lllll}
\hline & Normal group & LPS group & JKHL group & JKHH group \\
\hline Liver weight (mg) & $173.6 \pm 1.4^{\mathrm{d}}$ & $278.5 \pm 2.1^{\mathrm{a}}$ & $245.1 \pm 1.5^{\mathrm{b}}$ & $210.68 \pm 1.8^{\mathrm{c}}$ \\
Spleen weight (mg) & $89.9 \pm 0.8^{\mathrm{d}}$ & $136.4 \pm 1.2^{\mathrm{a}}$ & $110.7 \pm 1.8^{\mathrm{b}}$ & $98.49 \pm 1.4^{\mathrm{c}}$ \\
Mesenteric lymph nodes weight (mg) & $103.8 \pm 1.3^{\mathrm{d}}$ & $165.3 \pm 2.3^{\mathrm{a}}$ & $151.3 \pm 2.0^{\mathrm{b}}$ & $127.1 \pm 2.0^{c}$ \\
Mice body weight (g) & $30.5 \pm 0.1^{\mathrm{a}}$ & $23.1 \pm 0.3^{\mathrm{d}}$ & $25.6 \pm 0.2^{\mathrm{c}}$ & $28.8 \pm 0.2^{\mathrm{b}}$ \\
Liver indexes (\%) & $0.57^{\mathrm{d}}$ & $1.20^{\mathrm{a}}$ & $0.96^{\mathrm{b}}$ & $0.73^{\mathrm{c}}$ \\
Spleen indexes (\%) & $0.30^{\mathrm{d}}$ & $0.59^{\mathrm{a}}$ & $0.43^{\mathrm{b}}$ & $0.34^{\mathrm{c}}$ \\
Mesenteric lymph nodes indexes (\%) & $0.34^{\mathrm{d}}$ & $0.71^{\mathrm{a}}$ & $0.59^{\mathrm{b}}$ & $0.44^{\mathrm{c}}$ \\
\hline
\end{tabular}

Value presented are the mean \pm standard deviation

${ }^{a-d}$ Mean values with different letters in the same row are significantly different $(p<0.05)$ according to Duncan's multiple range test. LPS: 30 mg/kg BW injection on 15 days; JKHL, low dose of JKH (700 mg/kg BW) + LPS $30 \mathrm{mg} / \mathrm{kg}$ BW injection on 15 days; JKHH, high dose of JKH (2100 mg/kg BW) + LPS $30 \mathrm{mg} / \mathrm{kg}$ BW injection on 15 days

\section{Serum inflammatory cytokine analysis}

IL-1 $\beta$, IL-6, TNF- $\alpha$, and IFN- $\gamma$ are four typical proinflammatory cytokines, and the serum content of these four cytokines can indicate the degree of inflammation in the mouse body. The expression of pro-inflammatory cytokines in the four groups in Fig. 3 shows that the inflammation level of the normal group is the lowest of the four groups, and the inflammation level in the LPSinduced group is the highest of the four groups, with a value that is at least 1.7 times higher than the normal group, and the highest is six times greater. Gavage of JKH can alleviate the body's inflammatory response caused by LPS. Compared with the normal group, the inflammation level of the JKHH group was generally decreased to no more than twice that of the normal group.

\section{Colon bacteria translocation analysis}

When the intestinal mucosal barrier is damaged, the microorganisms and toxins in the intestine can break through the intestinal mucosal barrier and enter the portal vein and lymphatic system. Thereby, this will cause bacterial translocation and can even develop into systemic inflammatory response syndrome (SIRS) or multiple organ failure syndrome (MODS). Measuring the bacterial translocation in mice can reflect the degree of intestinal mucosal permeability. No bacterial translocation was detected in the liver, kidney, or MLN of mice in the normal group, but the positive rate of bacterial translocation in the liver, kidney, and MLN of mice in the LPS group exceeded $86 \%$. The intestinal permeability in JKH intervention mice was significantly decreased, and the positive rate of bacterial translocation in the liver, kidney, and MLN of the JKHH group mice was only 20\% (Table 3).

\section{Colonic permeability analysis}

The permeability of the intestinal mucosa in the normal group to fluorescent macromolecules was very small, at only $4.14 \pm 0.51 \mu \mathrm{g} / \mathrm{mL}$. The injection of LPS significantly increased the permeability of the intestinal mucosa to molecular substances. The concentration of fluorescent substances detected in the serum of the LPS-induced group mice was $69.88 \pm 1.79 \mu \mathrm{g} / \mathrm{mL}$, which was approximately 16.8 times that of the normal group mice. The concentration of fluorescent substances in the serum of the JKHL and JKHH group mice was 7.8 and 4.3 times that of the normal group, respectively, which was significantly lower than that of the LPS-induced group (Fig. 4).

\section{Colon histopathological observation}

In the normal group, the colon structure was clear, the mucosal epithelial cells were neatly arranged, the intestinal glands were regular, and the goblet cells were abundant. In the LPS group, the colonic mucosa of the mice was shedding and necrotic, forming ulcers of varying degrees, a large number of inflammatory cells infiltrated, mucosal glands were damaged, and the arrangement was sparse and disordered, with varying degrees of expansion. There was no obvious ulcer formation in the colonic mucosa of mice in the JKH group, and the mucosal edema and congestion and inflammatory cell infiltration were reduced. There was less damage to the high-dose and lower-dose groups (Fig. 5).

\section{mRNA and protein expression analysis of colon tissue}

In this experiment, the mRNA and protein expression of the five most important genes in tight junctions (TJs) were measured. The levels of mRNA and protein expressed by the five genes in the colon of the normal group of mice were the highest among the four groups of mice. The mRNA and protein expression of the five genes in the colon of mice from the LPS group was the lowest. JKH can alleviate the damage to TJs caused by LPS, and enhance the expression of mRNA and the proteins 

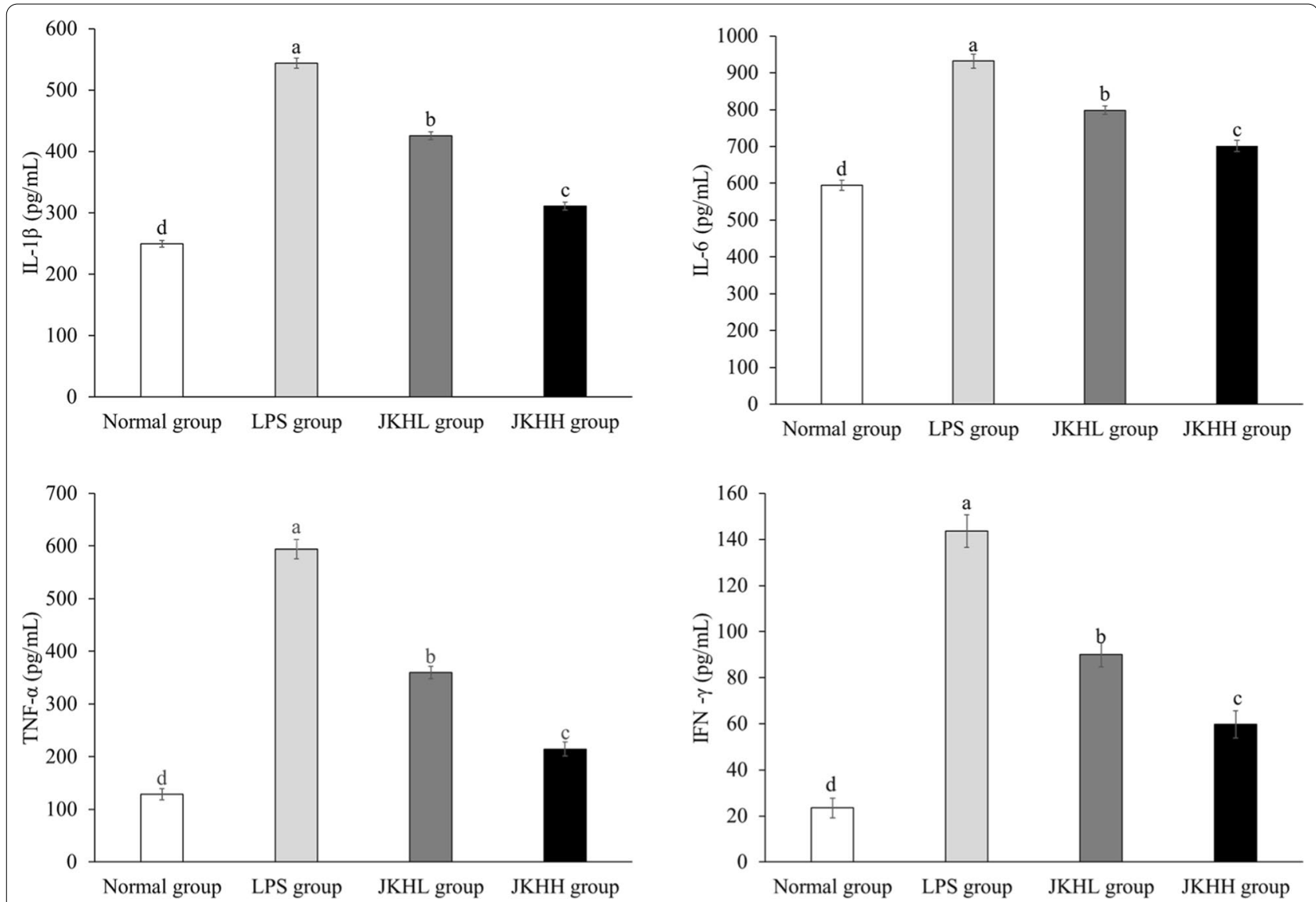

Fig. 3 Cytokine indexes in the serum of BALB/C mice that underwent LPS-induced colonic epithelial injury. ${ }^{a-d}$ Mean values with different letters in the different bar are significantly different $(\mathrm{p}<0.05)$ according to Duncan's multiple range test. LPS: $30 \mathrm{mg} / \mathrm{kg}$ BW injection on 15 days; JKHL, low dose of JKH (700 mg/kg BW) + LPS 30 mg/kg BW injection on 15 days; JKHH, high dose of JKH (2100 mg/kg BW) + LPS 30 mg/kg BW injection on 15 days

produced by the expression of the JAM-1, ZO-1, claudin-1, occludin, and cingulin genes (Fig. 6).

\section{Discussion}

JKH contains numerous herbal and food ingredients, among which radish leaves, ginger, and bamboo salt are food ingredients; plantain, Asian lizard's tail, white atractylodes, mistletoe, and cinnamon are considered as traditional Korean medicine ingredients; and Korean milk thistle, ginger, royal kombu, and Chaga mushroom are considered both medicine and food homology ingredients. In previous analysis and research, it was found that $\mathrm{JKH}$ contains a large amount of active ingredients with anti-inflammatory effects that also have a certain preventive effect on ulcerative colitis [1].

The intestine is not only an important organ for digestion and absorption, but it is also the largest immune organ in the body. It plays an important role in the body's non-specific anti-infection defense system [21]. The intestinal mucosa can monitor and remove intestinal bacteria, toxins, potentially harmful biological peptides, and food antigens to ensure the integrity of the body [22]. A complete intestinal mucosal barrier is the basis for maintaining the multiple functions of the intestine [23].

Table 3 Bacterial translocation in the liver, spleen, and mesenteric lymph node

Number of animals with/without translocation after LPS injection

\begin{tabular}{llll}
\hline & Liver & Spleen & MLN \\
\hline Normal group & $0 / 10^{\mathrm{a}}$ & $0 / 10^{\mathrm{a}}$ & $0 / 10^{\mathrm{a}}$ \\
LPS group & $8 / 2^{\mathrm{d}}$ & $9 / 1^{\mathrm{d}}$ & $9 / 1^{\mathrm{d}}$ \\
JKHL group & $5 / 5^{\mathrm{c}}$ & $6 / 4^{\mathrm{c}}$ & $7 / 3^{\mathrm{c}}$ \\
JKHH group & $2 / 8^{\mathrm{b}}$ & $2 / 8^{\mathrm{b}}$ & $2 / 8^{\mathrm{b}}$
\end{tabular}

Value presented are the mean \pm standard deviation

${ }^{a-d}$ Mean values with different letters in the same column are significantly different $(p<0.05)$ according to Duncan's multiple range test. LPS: $30 \mathrm{mg} / \mathrm{kg} \mathrm{BW}$ injection on 15 days; JKHL, low dose of JKH $(700 \mathrm{mg} / \mathrm{kg} \mathrm{BW})+\mathrm{LPS} 30 \mathrm{mg} / \mathrm{kg} \mathrm{BW}$ injection on 15 days; JKHH, high dose of JKH (2100 mg/kg BW) + LPS $30 \mathrm{mg} /$ $\mathrm{kg} \mathrm{BW}$ injection on 15 days 


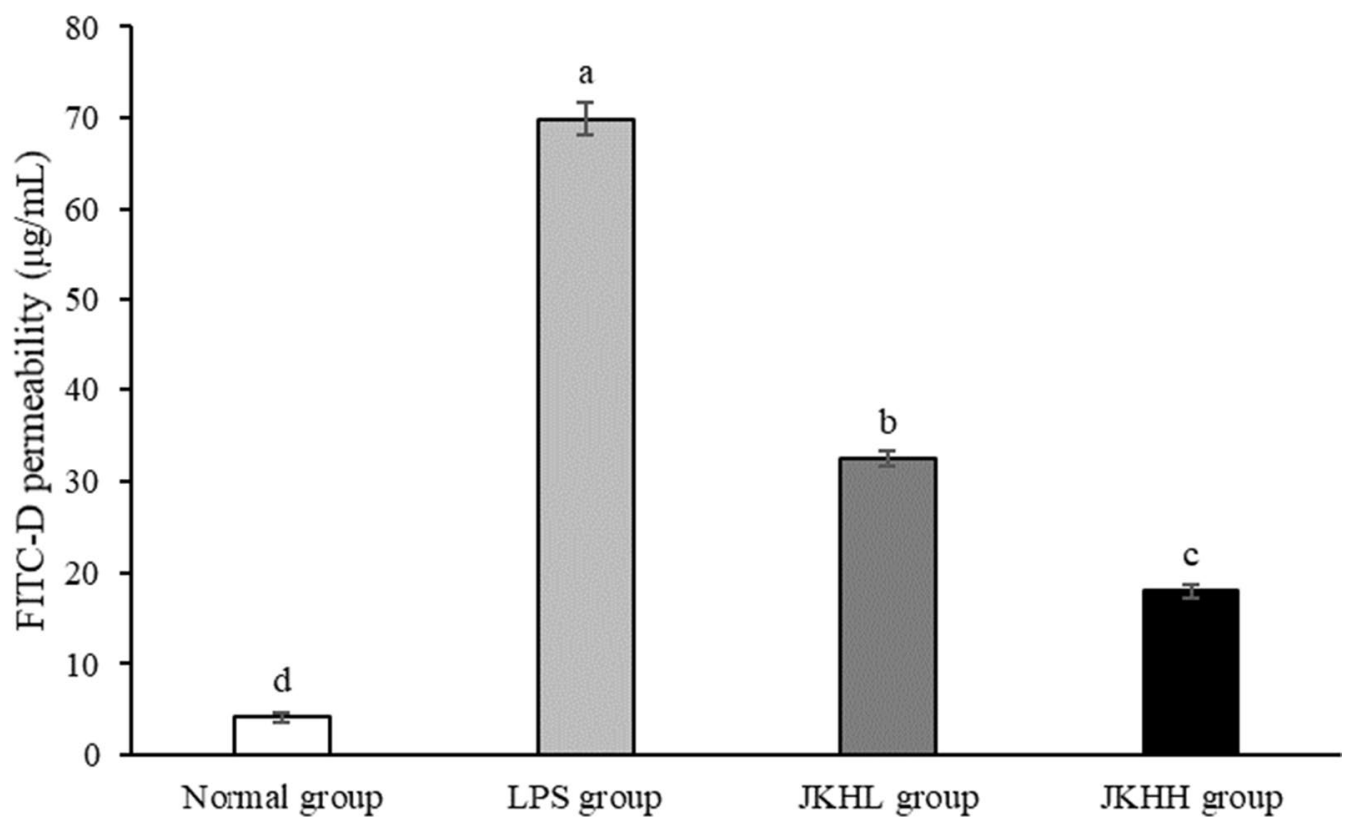

Fig. 4 Colon FITC-D permeability in BALB/C mice that underwent LPS-induced colonic epithelial injury. ${ }^{\text {a-d }}$ Mean values with different letters in the different bar are significantly different $(\mathrm{p}<0.05)$ according to Duncan's multiple range test. LPS: $30 \mathrm{mg} / \mathrm{kg}$ BW injection on 15 days; JKHL, low dose of $\mathrm{JKH}(700 \mathrm{mg} / \mathrm{kg} \mathrm{BW})+$ LPS 30 mg/kg BW injection on 15 days; JKHH, high dose of JKH (2100 mg/kg BW) + LPS 30 mg/kg BW injection on 15 days

The intestinal mucosal barrier is mainly composed of four parts: the biological barrier, chemical barrier, mechanical barrier, and immune barrier [24]. The biological barrier consists of the normal intestinal flora, such as Lactobacillus and Bifidobacterium [25]; the chemical barrier is mainly composed of mucus secreted by epithelial cells, as well as intestinal symbiotic bacteria, bile, lysozyme, probiotics, and substances secreted by various digestive enzymes [26]; the mechanical barrier is composed of TJs of intestinal epithelial cells and intestinal mucus [27]; and the immune barrier is mainly composed of secretory immunoglobulins, related lymphoid tissues of the digestive tract, and defensins [28]. These four barriers constitute a huge and complex three-dimensional protective system for the intestines, in which the synergy between the mechanical barrier and the immune barrier is the core of maintaining the homeostasis of the intestinal environment [29]. Therefore, the protection of the intestinal mucosal barrier function is very important, and the use of natural food and drug ingredients for intestinal mucosal protection has become a heavily researched area.

As the main component of the cell wall of gram-negative bacteria, LPS itself has no toxic effects, but when LPS enters the body's circulatory system, interaction with host cells occurs that results in stimulation of immune cells and subsequent synthesis and release of inflammatory factors, thereby exhibiting biological activity
[30-32]. LPS usually acts on systemic inflammation, but may also cause gastrointestinal mucosal injury, the intestine is one of the target organs of LPS [33-35]. LPS can directly trigger the inflammatory response of intestinal epithelial cells, destroy the integrity of the intestinal mucosal barrier, and cause mucosal barrier dysfunction [36-38]. It is clear from our experimental data that the intervention of $\mathrm{JKH}$ increases the food intake of mice, reduces the severity of mouse diarrhea, reduces the level of inflammatory factors in the serum of mice, increases the permeability of the intestinal mucosa, prevents bacteria and other macromolecular substances from entering the lumen circulation, and maintains the integrity of intestinal epithelial cells.

In the intestinal mucosal barrier, the most important barrier is the mechanical barrier, which is composed of intact intestinal epithelial cells and TJs between adjacent intestinal epithelial cells [39]. The TJ is a protein complex composed of a group of transmembrane proteins (including occludin and claudin), zonula occludens (ZO) proteins, and junction adhesion molecules (JAM) [40]. It is a barrier that selectively allows the diffusion of molecules and ions between cells [41]. Its opening and closing are regulated by various physiological and pathological stimuli such as intestinal lumen materials and cytokines, and it plays an important role in maintaining normal intestinal mucosal epithelial permeability [42]. It allows the required dietary nutrients, electrolytes, and water 


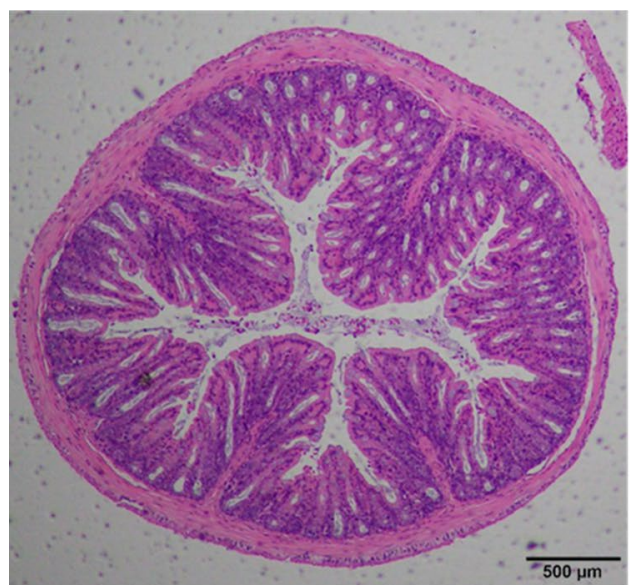

Normal group

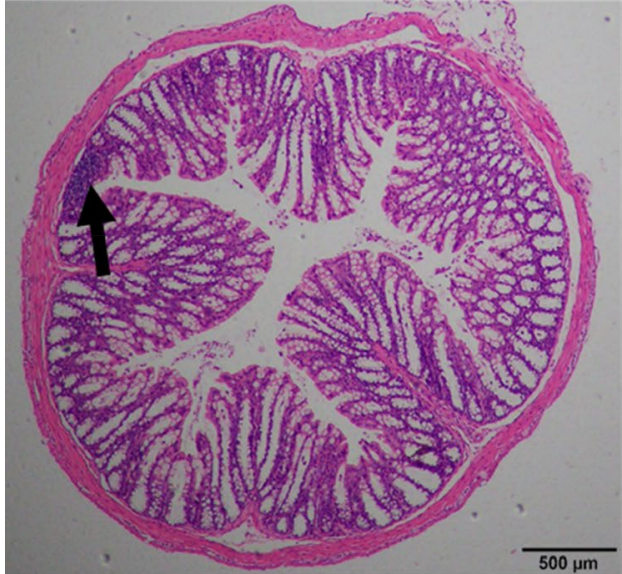

JKHL group

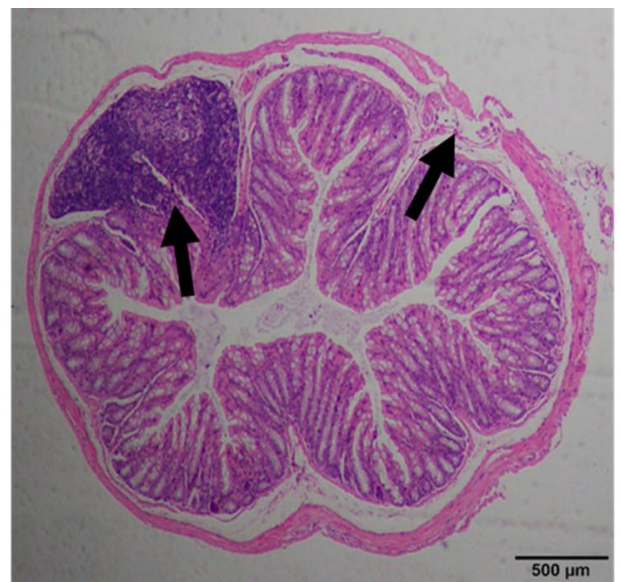

LPS group

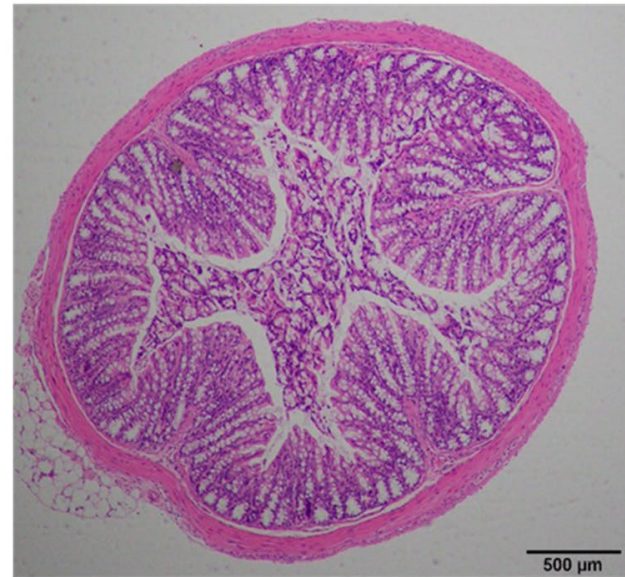

JKHH group

Fig. 5 Pathological observation by H\&E staining of colon tissue from BALB/C mice that were subject to LPS-induced colonic epithelial injury. The arrow in the picture indicates the inflammatory and damaged parts of the colon. LPS: $30 \mathrm{mg} / \mathrm{kg} \mathrm{BW}$ injection on 15 days; JKHL, low dose of JKH (700 mg/kg BW) + LPS 30 mg/kg BW injection on 15 days; JKHH, high dose of JKH (2100 mg/kg BW) + LPS 30 mg/kg BW injection on 15 days

to enter the cavity to circulate, and prevents the entry of foreign antigens, microorganisms, and their toxins [43]. If the intestinal mucosal barrier is damaged, it will cause the destruction of the TJ between epithelial cells and increase the permeability [44]. Due to the increased permeability, the intestinal mucosa is more susceptible to constant stimulation by pathogens, bacterial toxins, microorganisms, and other factors, thereby promoting the recruitment of neutrophils, leading to the release of excessive inflammatory mediators and causing further damage to the intestinal tissues $[45,46]$.

Studies have confirmed that the claudin and occludin proteins are important components of TJs [47]. Under normal conditions, occludin is located on the top of the sidewall of epithelial cells, separating the top and basal sides of the cells, and preventing the material in the epithelial intercellular space from overflowing and macromolecules from passing through the intercellular space [48]. The claudin protein is considered to be the backbone of TJs and plays an important role in the ability of TJs to seal cell spaces [49]. The JAM-1 protein is located at the top of the intercellular space and plays an important role in the inflammation process [50]. The expression of JAM protein is usually related to the recruitment of $\mathrm{TJ}$ components, and it also supports the $\mathrm{TJ}$ assembly [51]. ZO-1 is also one of the important components of TJs. It is involved in regulating cell material transport and maintaining epithelial polarity, and is also related to information transmission and regulation of processes such as cell proliferation and differentiation, tumor cell 


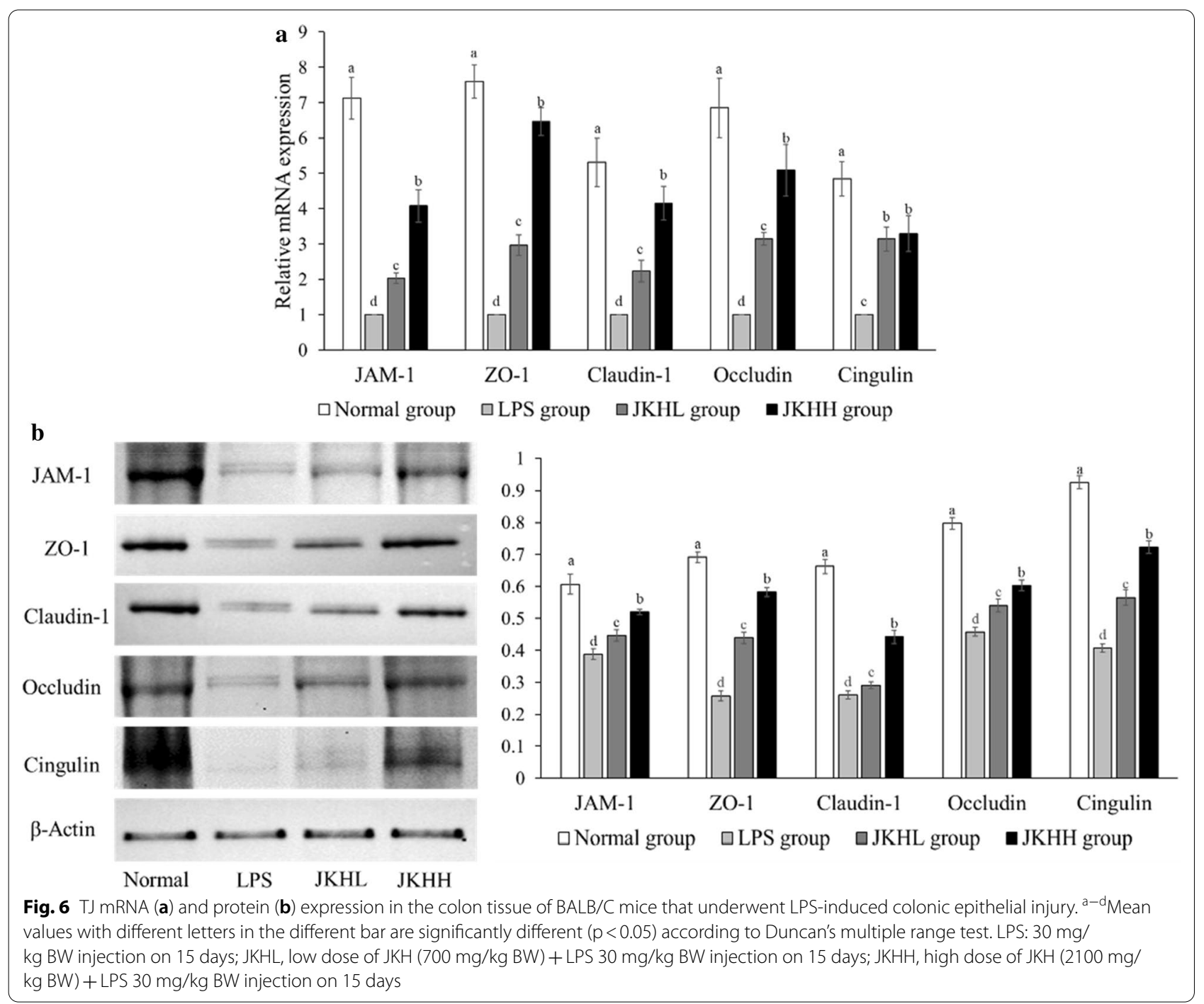

metastasis, and gene transcription [52]. Cingulin binds to bundle actin filaments and forms a bundle that interacts with myosin II and several TJ proteins, including ZO-1, $\mathrm{ZO}-2$, ZO-3, and occludin [53]. In addition, cingulin forms a complex with the TJ membrane protein JAM-1 that acts on TJs together [54].

In patients with active inflammatory bowel disease with impaired intestinal epithelial barrier function, the expression of mRNA and TJ proteins, such as occludin, claudin-1, ZO-1, cingulin, and JAM-1, was significantly reduced in the lamina propria of the colonic mucosa. The mRNA and protein expression of occludin, claudin-1, ZO-1, and JAM-1, which are important components of TJs, significantly increased in the colon tissue of mice treated with JKH. This indicates that JKH can maintain the composition of the $\mathrm{TJ}$ and the shape of the intestinal epithelial barrier, so as to protect the intestinal mucosal barrier.
Our experiments have confirmed that the traditional Korean medicinal food JKH alleviates the functional damage of mouse colonic epithelial cells caused by LPS, effectively reduces the inflammation in the mouse intestine, and also protects the normal function and state of the mouse colon. It also can prevent bacterial displacement caused by colon damage. Additionally, JKH alleviated the weight loss and decreased food intake, and also protected the $\mathrm{TJ}$ tissues of the mouse colon and the tissues of other body organs. In future research, we will further determine the effective ingredients in $\mathrm{JKH}$ and the mechanism used by each ingredient to protect the colon. Our data indicate that there is great potential for the use of $\mathrm{JKH}$ as a supplementary food in the treatment of patients with colon injury so that they can quickly restore their health

Acknowledgements

Not applicable. 


\section{Authors' contributions}

Conception and study design: $X Y L$; Data acquisition: $X Y L, Y K M$; Data analysis: TY, RKY; Manuscript drafting: XYL; Manuscript revising: XZ, KYP. All authors read and approved the final manuscript.

\section{Funding}

This work was supported by the GRRC program of Gyeonggi province. [GRRCCHA2017-B03, Development of Functional Kimchi and Taemyeongcheong Beverage as a Functional Food and Dietary Supplement].

\section{Availability of data and materials}

All data generated or analyzed during this study are included in this article. The datasets used and/or analyzed during the current study are available from the corresponding author on reasonable request.

\section{Declarations}

\section{Competing interests}

The authors declare that they have no conflicts of interest.

\section{Author details}

'Department of Food Science and Biotechnology, Cha University, Seongnam, Gyeonggi-do 13488, South Korea. ${ }^{2}$ Chongqing Collaborative Innovation Center for Functional Food, Chongqing Engineering Research Center of Functional Food, Chongqing Engineering Laboratory for Research and Development of Functional Food, Chongqing University of Education, Chongqing 400067, People's Republic of China. ${ }^{3}$ Phytogenics Co., Ltd., Seongnam, Gyeonggi-Do 13522, South Korea.

Received: 2 August 2021 Accepted: 25 October 2021

Published online: 05 November 2021

\section{References}

1. Long X, Kim YG, Pyo YK, Yi R, Xin Z, Park KY (2020) Inhibitory effect of Jangkanghwan (Korean traditional food) on experimental ulcerative colitis in mice. J Food Biochem 44:e13488

2. Islam MN, Ishita IJ, Jin SE, Choi RJ, Lee CM, Kim YS, Jung HA, Choi JS (2013) Anti-inflammatory activity of edible brown alga Saccharina japonica and its constituents pheophorbide a and pheophytin a in LPS-stimulated RAW 264.7 macrophage cells. Food Chem Toxicol 55:541-548

3. Stermitz FR, Tawara-Matsuda J, Lorenz P, Mueller P, Zenewicz L, Lewis K (2000) 5'-Methoxyhydnocarpin-D and pheophorbide A: Berberis species components that potentiate berberine growth inhibition of resistant Staphylococcus aureus. J Nat Prod 63:1146-1149

4. Kandagatla SK, UhI RT, Graf TN, Oberlies NH, Raner GM (2019) Pheophorbide derivatives isolated from açaí berries (Euterpea oleracea) activate an antioxidant response element in vitro. Nat Prod Commun. https://doi. org/10.1177/1934578X1985244314

5. Chan JY, Tang PM, Hon PM, Au SW, Tsui SK, Waye MM, Kong SK, Mak TC, Fung KP (2006) Pheophorbide a, a major antitumor component purified from Scutellaria barbata, induces apoptosis in human hepatocellular carcinoma cells. Planta Med 72:28-33

6. Tao Y, Yue M, Lv C, Yun X, Qiao S, Fang Y, Wei Z, Xia Y, Dai Y (2020) Pharmacological activation of $E R \beta$ by arctigenin maintains the integrity of intestinal epithelial barrier in inflammatory bowel diseases. Faseb J 34:3069-3090

7. Wang TM, Fu Y, Yu WJ, Chen C, Di X, Zhang H, Zhai YJ, Chu ZY, Kang TG, Chen HB (2017) Identification of polar constituents in the decoction of Juglans mandshurica and in the medicated egg prepared with the decoction by HPLC-Q-TOF MS². Molecules 22:1452

8. Li S, He Y, Zhang H, Zheng R, Xu R, Liu Q, Tang S, Ke X, Huang M (2020) Formulation of traditional Chinese medicine and its application on intestinal flora of constipated rats. Microb Cell Fact 19:212

9. Lin X, Shao T, Huang L, Wen X, Wang M, Wen C, He Z (2020) Simiao decoction alleviates gouty arthritis by modulating proinflammatory cytokines and the gut ecosystem. Front Pharmacol 11:955

10. Yu M, Jia HM, Zhang T, Shang H, Zhang HW, Ma LY, Zou ZM (2020) Gut microbiota is the key to the antidepressant effect of Chaihu-Shu-GanSan. Metabolites 10:63
11. Gurib-Fakim A (2006) Medicinal plants: traditions of yesterday and drugs of tomorrow. Mol Aspects Med 27:1-93

12. Wang XM, Li XB, Peng Y (2017) Impact of Qi-invigorating traditional Chinese medicines on intestinal flora: a basis for rational choice of prebiotics. Chin J Nat Med 15:241-254

13. Busti S, Rossi B, Volpe E, Ciulli S, Piva A, D'Amico F, Soverini M, Candela M, Gatta PP, Bonaldo A, Grilli E, Parma L (2020) Effects of dietary organic acids and nature identical compounds on growth, immune parameters and gut microbiota of European sea bass. Sci Rep 10:21321

14. Turner JR (2009) Intestinal mucosal barrier function in health and disease. Nat Rev Immunol 9:799-809

15. König J, Wells J, Cani PD, García-Ródenas CL, MacDonald T, Mercenier A, Whyte J, Troost F, Brummer RJ (2016) Human intestinal barrier function in health and disease. Clin Transl Gastroenterol 7:e196

16. Tlaskalová-Hogenová H, Stepánková R, Hudcovic T, Tucková L, Cukrowska B, Lodinová-Zádníková R, Kozáková H, Rossmann P, Bártová J, Sokol D, Funda DP, Borovská D, Reháková Z, Sinkora J, Hofman J, Drastich P, Kokesová A (2004) Commensal bacteria (normal microflora), mucosal immunity and chronic inflammatory and autoimmune diseases. Immunol Lett 93:97-108

17. Balzan S, de Almeida QC, de Cleva R, Zilberstein B, Cecconello I (2007) Bacterial translocation: overview of mechanisms and clinical impact. J Gastroenterol Hepatol 22:464-471

18. Yang X-J, Qian J-X, Wei Y, Guo Q, Jin J, Sun X, Liu S-L, Xu C-F, Zhang G-X (2018) Tanshinone IIA sodium sulfonate attenuates LPS-induced intestinal injury in mice. Gastroent Res Pract 2018:9867150

19. Moriez R, Salvador-Cartier C, Theodorou V, Fioramonti J, Eutamene H, Bueno L (2005) Myosin light chain kinase is involved in lipopolysaccharide-induced disruption of colonic epithelial barrier and bacterial translocation in rats. Am J Pathol 167:1071-1079

20. Zayat M, Lichtenberger LM, Dial EJ (2008) Pathophysiology of LPSinduced gastrointestinal injury in the rat: role of secretory phospholipase A2. Shock 30:206-211

21. Miao RX, Zhu XX, Wan CM, Wang ZL, Wen Y, Li YY (2018) Effect of Clostridium butyricum supplementation on the development of intestinal flora and the immune system of neonatal mice. Exp Ther Med 15:1081-1086

22. Acheson DW, Luccioli S (2004) Microbial-gut interactions in health and disease. Mucosal immune responses. Best Pract Res Clin Gastroenterol 18:387-404

23. Chen H, Mao X, He J, Yu B, Huang Z, Yu J, Zheng P, Chen D (2013) Dietary fibre affects intestinal mucosal barrier function and regulates intestinal bacteria in weaning piglets. Br J Nutr 110:1837-1848

24. Ren Z, Guo C, Yu S, Zhu L, Wang Y, Hu H, Deng J (2019) Progress in mycotoxins affecting intestinal mucosal barrier function. Int J Mol Sci 20:2777

25. Ohland CL, Macnaughton WK (2010) Probiotic bacteria and intestinal epithelial barrier function. Am J Physiol Gastrointest Liver Physiol 298:G807-G819

26. Yin J, Sheng B, Yang K, Sun L, Xiao W, Yang H (2019) The protective roles of NLRP6 in intestinal epithelial cells. Cell Prolif 52:e12555

27. Chelakkot C, Ghim J, Ryu SH (2018) Mechanisms regulating intestinal barrier integrity and its pathological implications. Exp Mol Med 50:1-9

28. Peterson LW, Artis D (2014) Intestinal epithelial cells: regulators of barrier function and immune homeostasis. Nat Rev Immunol 14:141-153

29. Jin M, Zhu Y, Shao D, Zhao K, Xu C, Li Q, Yang H, Huang Q, Shi J (2017) Effects of polysaccharide from mycelia of Ganoderma lucidum on intestinal barrier functions of rats. Int J Biol Macromol 94:1-9

30. Loke MF, Ng CG, Vilashni Y, Lim J, Ho B (2016) Understanding the dimorphic lifestyles of human gastric pathogen Helicobacter pylori using the SWATH-based proteomics approach. Sci Rep 6:26784

31. Chen W, Luo S, Xie P, Hou T, Yu T, Fu X (2018) Overexpressed UCP2 regulates mitochondrial flashes and reverses lipopolysaccharide-induced cardiomyocytes injury. Am J Transl Res 10:1347-1356

32. Otto DP, de Villiers MM (2020) Layer-by-layer nanocoating of antiviral polysaccharides on surfaces to prevent coronavirus infections. Molecules 25:3451

33. Xiao Z, Liu L, Jin Y, Pei X, Sun W, Wang M (2021) Clostridium tyrobutyricum protects against LPS-induced colonic inflammation via IL-22 signaling in mice. Nutrients 13:215

34. Xu J, Liu Z, Zhan W, Jiang R, Yang C, Zhan H, Xiong Y (2017) Recombinant TsP53 modulates intestinal epithelial barrier integrity via upregulation of ZO-1 in LPS-induced septic mice. Mol Med Rep 17:1212-1218 
35. Li R, Zhou R, Wang H, Li W, Pan M, Yao X, Zhan W, Yang S, Xu L, Ding Y, Zhao L (2019) Gut microbiota-stimulated cathepsin K secretion mediates TLR4-dependent M2 macrophage polarization and promotes tumor metastasis in colorectal cancer. Cell Death Differ 26:2447-2463

36. Li S, Intini G, Bobek LA (2006) Modulation of MUC7 mucin expression by exogenous factors in airway cells in vitro and in vivo. Am J Respir Cell Mol Biol 35:95-102

37. Sun J, Zhao F, Lin B, Feng J, Wu X, Liu Y, Zhao L, Zhu B, Wei Y (2020) Gut microbiota participates in antithyroid drug induced liver injury through the lipopolysaccharide related signaling pathway. Front Pharmacol 11:598170

38. Goeritzer M, Bernhart E, Plastira I (2020) Myeloperoxidase and septic conditions disrupt sphingolipid homeostasis in murine brain capillaries in vivo and immortalized human brain endothelial cells in vitro. Int J Mol Sci 21:1143

39. Zhao HB, Jia L, Yan QQ, Deng Q, Wei B (2020) Effect of Clostridium butyricum and butyrate on intestinal barrier functions: study of a rat model of severe acute pancreatitis with intra-abdominal hypertension. Front Physiol 11:561061

40. Wan Y, Fu Y, Wang F, Sinclair AJ, Li D (2018) Protective effects of a lipid extract from hard-shelled mussel (Mytilus coruscus) on intestinal integrity after lipopolysaccharide challenge in mice. Nutrients 10:860

41. Chang YN, Liang Y, Xia S, Bai X, Zhang J, Kong J, Chen K, Li J, Xing G (2020) The high permeability of nanocarriers crossing the enterocyte layer by regulation of the surface zonal pattern. Molecules 25:919

42. Ibrahim D, Sewid AH, Arisha AH, Abd El-Fattah AH, Abdelaziz AM, Al-Jabr OA, Kishawy ATY (2020) Influence of Glycyrrhiza glabra extract on growth, gene expression of gut integrity, and Campylobacter jejuni colonization in broiler chickens. Front Vet Sci 7:612063

43. Moussa L, Demarquay C, Réthoré G, Benadjaoud MA, Siñeriz F, Pattapa G, Guicheux J, Weiss P, Barritault D, Mathieu N (2019) Heparan sulfate mimetics: a new way to optimize therapeutic effects of hydrogel-embedded mesenchymal stromal cells in colonic radiation-induced damage. Sci Rep 9:164

44. Pei LY, Ke YS, Zhao HH, Wang L, Jia C, Liu WZ, Fu QH, Shi MN, Cui J, Li SC (2019) Role of colonic microbiota in the pathogenesis of ulcerative colitis. BMC Gastroenterol 19:10
45. Wei C, Wang JY, Xiong F, Wu BH, Luo MH, Yu ZC, Liu TT, Li DF, Tang Q, Li YX, Zhang DG, Xu ZL, Jin HT, Wang LS, Yao J (2021) Curcumin ameliorates DSS-induced colitis in mice by regulating the Treg/Th17 signaling pathway. Mol Med Rep 23:34

46. Shu X, Zhang J, Wang Q, Xu Z, Yu T (2016) Glutamine decreases intestinal mucosal injury in a rat model of intestinal ischemia-reperfusion by downregulating HMGB1 and inflammatory cytokine expression. Exp Ther Med $12: 1367-1372$

47. Yi X, Xu C, Huang P, Zhang L, Qing T, Li J, Wang C, Zeng T, Lu J, Han Z (2020) 1-Trifluoromethoxyphenyl-3-(1-propionylpiperidin-4-yl) urea protects the blood-brain barrier against ischemic injury by upregulating tight junction protein expression, mitigating apoptosis and inflammation in vivo and in vitro model. Front Pharmacol 11:1197

48. Feldman GJ, Mullin JM, Ryan MP (2005) Occludin: structure, function and regulation. Adv Drug Deliv Rev 57:883-917

49. Garcia-Hernandez V, Quiros M, Nusrat A (2017) Intestinal epithelial claudins: expression and regulation in homeostasis and inflammation. Ann N Y Acad Sci 1397:66-79

50. Naik UP, Eckfeld K (2003) Junctional adhesion molecule 1 (JAM-1). J Biol Regul Homeost Agents 17:341-347

51. Bazzoni G (2003) The JAM family of junctional adhesion molecules. Curr Opin Cell Biol 15:525-530

52. Schwayer C, Shamipour S, Pranjic-Ferscha K, Schauer A, Balda M, Tada M, Matter K, Heisenberg CP (2019) Mechanosensation of tight junctions depends on ZO-1 phase separation and flow. Cell 179:937-52.e18

53. D'Atri F, Citi S (2001) Cingulin interacts with F-actin in vitro. FEBS Lett 507:21-24

54. Zahraoui A, Louvard D, Galli T (2000) Tight junction, a platform for trafficking and signaling protein complexes. J Cell Biol 151:F31-F36

\section{Publisher's Note}

Springer Nature remains neutral with regard to jurisdictional claims in published maps and institutional affiliations.

\section{Submit your manuscript to a SpringerOpen ${ }^{\circ}$ journal and benefit from:}

- Convenient online submission

- Rigorous peer review

- Open access: articles freely available online

- High visibility within the field

- Retaining the copyright to your article

Submit your next manuscript at springeropen.com 